Simona MITROIU

Institute of Interdisciplinary Research, “Alexandru Ioan Cuza” University of Iaşi

Iași, Romania

monmitroiu@yahoo.com

\title{
CHALLENGING THE ROMA STRUCTURAL DISCRIMINATION: DETERRITORIALIZATION PRACTICES IN ROMANIAN CINEMA
}

Recommended Citation: Mitroiu, Simona. "Challenging the Roma Structural Discrimination: Deterritorialization Practices in Romanian Cinema”. Metacritic Journal for Comparative Studies and Theory 7.2 (2021). Doi: https://doi.org/10.24193/mjcst.2021.12.03

Abstract: This paper examines the cinematographic reworking of memory spaces associated with power relations and structural injustice. The way in which space is represented and used as a medium that reflects power relations allows to question the space itself in cultural productions from Central-Eastern Europe when associated with Romani people (space and power relations, memory of slavery and discrimination, space and freedom, territoriality, space and its inhabitants, non-belonging, segregation, etc.). The paper focuses on motion pictures produced in the last decade in Romania, a prolific period due to the increasing interest for memory activism and to the multiplication of the cultural exploration of challenging topics. It aims to identify narrative, visual, and aesthetic expressions used as deterritorialization practices to stimulate relational remembrance and engagement with ongoing social inequality and structural injustice. Two short films - Alina Șerban's Bilet de iertare (Letter of forgiveness) and Adrian Silișteanu's Scris/Nescris (Written/Unwritten) - and a western type film - Radu Jude's Aferim!, winner of the Silver Bear for Best director at Berlinale in 2015, are analysed here.

Keywords: Roma, structural injustice, territoriality, decolonial stance, intersectionality, Romanian cinematographic representations. 
By adding substance to the memory regimes (social, cultural, collective) and by addressing issues related to discrimination, inequality and structural injustice, cultural productions can empower vulnerable individuals and communities. Cinema is part of history as a discourse on the past (Mazierska 1) and by reproducing microhistories, films present past social structures and social codes (Davis), power relations and their longlasting effects. Media studies offer a wide understanding of the capacity of literature and film to represent a traumatic past in a mediated form (Erll, Traumatic pasts). Moreover, visual productions can stimulate dialogical memories and support, through artistic forms of expression, new grassroots politics (Asavei 2019, 3); they can focus on vulnerability and marginality using a wide range of artistic expressions and supporting the audience's apprehension of continuing discrimination. Using a decolonial stance defined as involving a "conscious choice of how to interpret reality and how to act upon it" (Tlostanova 19), this paper analyses several cinema productions addressing Roma histories and experiences in order to identify narrative, visual and aesthetic expressions of power relations, used as deterritorialization practices in order to stimulate relational remembrance and engagement with past and current social inequality and hermeneutical injustice (see Fricker). The issue of the Roma's access and right to memory cannot be understood without considering the "constant suppression of Roma history and memory, social injustice, and pandemic Romaphobia” (Asavei 2020, 108) that continue to dominate the media discourse (see Trehan and Kóczé; van Baar). However, how can visual cinematographic representations avoid reproducing the official narrative and the public discourse that generate ongoing structural inequality and discrimination? A significant effort to depart from the general stereotypical and discriminative narrative - propagated even in institutional forms following the disregard of historical injustices and through strategic politics of oblivion (Asavei 2019, 11) - is necessary.

Roma people are considered one of the most socio-economically vulnerable populations in Europe. The three films analysed - Aferim! (Radu Jude, RO/B/CZ/F 2015), Written/Unwritten (Adrian Silișteanu, RO 2016), Letter of Forgiveness (Alina Şerban, 2020 RO) - address the topic of territoriality and the adjacent non-belonging state of existence resulting from the social exclusion and marginality associated with the 47 
Roma. The films are contextualised in the framework of memory studies, as an exploration of the cultural and social memory of the region, with its variations and polyphonic nature. By conceptually connecting territoriality and structural injustice, segregation and displacement, this paper aims to analyse and to highlight the cinema narratives and visual expressions that mediate the understanding of past inequalities and actively address ongoing discrimination. Alongside cultural memory analyses (see Pickering; Till; Radstone), the film studies approach - examining film as a text - is used. Therefore, a close reading based on film textual analysis is applied for the three selected films. A number of interconnected visual expressions and narratives are identified and discussed as deterritorialization practices, a vision influenced by the deterritorialization of memory as being effected through media of circulation (Erll, Travelling memory). As Habiba Hadziavdic and Hilde Hoffmann write "the images of Roma in film have been produced primarily by non-Roma, and (...) only recently have scholars and activists from different fields critically addressed filmic misrepresentations" (704). Therefore, special attention is given to cinematographic productions directed by Roma directors and featuring Roma actors. The gender dimension perspective is also prioritized through analyses focused on producers, as well as on cinematographic images, representations, and topics addressed. The images and representations of Roma in cinema and art productions are indebted to a labelling model (portraying nomadic lifestyle, patriarchal power structures within extended families, coerced urbanisation, travelling and poverty) (see Iordanova; Imre; Gay Y Blasco), and situated under the direct influence of the exoticism and Orientalism paradigm (see for example Jelača; Murtic; Bogdal; Asavei 2019). Roma women have also been prone to being visually represented solely through this exoticism paradigm, which reduces their lives and experiences of oppression and violence to stereotypical representations and images. They are portrayed as mysterious, sexually alluring, and as dealing with magic (Falkowska and Loska; Hadziavdic and Hoffmann; Asavei 2019). Hadziavdic and Hoffmann define film as a "polysemic field of negotiation and battle for meaning and the production of knowledge" (703) and examine specific sites and places as "ethnic" markers. They discuss the spaces of alterity in early cinema and examine these representations and their developments and tropes in recent films. The research proposed here aims to move forward the discussion by analysing cinematographic 
deterritorialization practices as forms of memory activism, as an endeavour to incite and support the audience's self-assessment about challenging histories and ongoing discrimination and inequality.

Aferim! (2015), directed by Radu Jude and winner of the Silver Bear for Best director at Berlinale, follows the journey of constable Constandin and his adult son Ioniță, hired by the boyar Iordache to search for a runaway Roma slave, Carfin. Having apprehended the fugitive, the father-and-son team finds out, at the same time with the audience, that Carfin had run away as result of the boyar's discovery of his affair with the boyar's wife, who had used her position of power to instigate the affair. The journey itself depicts the state of affairs in the Romanian territories (Wallachia in 1835), the social hierarchy and inter-ethnic relations, the social structure and behaviour patterns, the people's understanding of laws and their everyday life. Constandin is a mature man who is in a position to convey to his son his own knowledge about life. Therefore, the journey takes place not only in a physical space, but also in the space of memories and popular culture. His character deceitfully engages with the spectators and the critics' empathy (Goff; Kiang; Hoffman), making them acknowledge his attempts to do good, even if a close reading shows that these attempts always remain at a declarative level. For example, one the one hand, Constandin is sympathetic to the slaves' sufferance: he assures the child slave Tintiric, a runaway boy found together with Carfin, that he will have a good life, he calms down Carfin by promising that he will intervene to moderate in the future the beatings inflicted by the boyar, he also promises, both to Carfin and to the boyar's wife, who had been beaten and physically restrained by her husband, that he himself will guarantee the compliance to the existing rules, etc. On the other hand, his permanent and gratuitous verbal and physical brutality contradicts all its verbal promises. He is a guardian of the law who easily and repeatedly breaks the law, he has no power to intervene when the boyar breaks the law by continuing to mistreat his wife, and the lawbreaking culminates with the brutal castration of Carfin. Poverty, physical and verbal abuses, the intentional lawbreaking, especially by those representing the authority, discrimination and injustice characterize the world depicted by Aferim!, and the Roma slaves are the lowest category of this oppressive hierarchy of existence. The film points to the long history of Roma discrimination, to its structural nature, and to 
the general population's role in perpetuating and generating intersectional dimensions of inequality.

Letter of Forgiveness (2020) is a short film directed by the Romanian Roma actor, activist, writer and director Alina Șerban as part of a larger project focused on Roma exclusion and structural discrimination. Şerban is one of the most active directors, writers and actors in promoting Roma rights and publicly discussing the ongoing discrimination of the Roma community. Letter tells the story of a mother and a brilliant well-educated son, both slaves in a household of a wealthy Romanian noblewoman a year before the abolition of slavery in the Romanian Principalities (Moldova and Wallachia - 1855-1856). A 'letter of forgiveness' was a document through which a slave was 'forgiven,' freed from slavery. Maria, the mother, has already been 'forgiven' by the former deceased master, but she hides her letter as she cannot bring herself to leave her son behind. She plans to try to free her son Dinca from slavery, and the film reveals her inner struggle, the external social world and the same problematic relationship between justice and regulations and those who are supposed to implement them. However, the film shows that those well-educated and in a position to call for the abolition of slavery (and, furthermore, invested with legislative power) easily discard the equality and freedom principles and justice requirements when their own social category is involved. The rigid social structure is bound to the same hierarchy of existence that designates the Roma slave's life as expendable when the social class interests (even the sentimental ones) prevail. Şerban uses the interconnections between the physical world and the human expressions, to illustrate the structural inequality and discrimination that strangled and undermined the Romas' individual agency and the Roma community's development.

Adrian Silișteanu's Written/Unwritten (2016), including both Romani and Romanian language dalogue, points directly to the geographical, social and cultural segregation. The film is constructed around the topic of official papers attesting institutional and national belonging. The structural inequality takes multiple forms and has various manifestations: from having children at a very young age and dropping out of school, to patriarchal behaviour, conformism, stereotypes and official documents attesting identity and nationality. A Roma underage girl, Alexandra Duduianu, gives birth to a baby girl and the official documents that are required to be filled by the 
hospital personnel put the family under pressure. The young mother does not yet have her ID card (normally issued for every Romanian citizen at the age of 14), and her mother and father prove in fact to be her grandparents, as her natural mother abandoned her and her sister in their childhood. The hospital personnel push the family to call for social assistance and try to separate the baby girl from her family as no documents attest their connections and the family status of the child. The grandfather travels together with his other daughter/granddaughter in order to find the natural mother, his actual daughter, and bring her to the hospital to certify the blood connection and to sign the documents for the baby girl. The belonging and identity relationship in terms of structural injustice is questioned. In a short interview at the Transylvania International Film Festival (2017) Silișteanu recounts the real story that inspired him as he witnessed it in a Romanian hospital; he also spoke about the fact he does not understand Romani language, but that he had trusted the Roma actors to follow his directions, although he admits that some improvisation has occurred.

\section{Structural injustice and colonial space}

The Roma population was present in Romanian lands (Walachia and Moldova) from the second half of the fourteenth century onwards, the earliest written information dating from 1385 when forty Roma families were mentioned among the possessions bequeathed to a monastery (Achim 13). Slavery is mentioned for the first time in a document dating from 1445 as part of the country's social system (Achim 87); slaves were a cheap and reliable labour force, bond to their masters - boyars, monasteries and landowners (Achim 49). They were the lowest rung of the all-subjugated classes; no status as a legal person was granted and slaves were listed as chattel - their masters' property. Even if a law regarding slaves (including several norms covering just their obligations, applicable punishments and authorities governing this punishment system) was supposed to regulate their lives, the masters continuously abused their rights, infringing even these regulations. The abuses, including forms of violence and sexual exploitation endured by Roma women, are rarely recorded in any type of documents. Unfortunately, the slave status, unchanged until the mid-nineteenth century, underpinned the Roma low and marginal social position (Achim 1). Despite the progress recorded by the Romanian society under the influence of the general directions 
established across Central and Eastern Europe, for four centuries the lifestyle of the Roma population remained unchanged and these evolutions had limited effect on the Roma slaves (Achim 87).

The question of land and property was correlated at this level with social status; the absence of land property or land connection was socially treated as a factor determining the low social position and the adjacent non-belonging. The Romanian peasant serfs were bound to the land, the Roma slaves were bound to their owners, they were mere chattel and thus could be sold, given away, etc. Land ownership was "the basic condition for social and juridical freedom," "the prerequisite for full citizenship" and a right denied to the Roma population, therefore the relationship between territory, citizenship and belonging was exclusionary, and only after the abolition of slavery the Roma could live as inhabitants of town and cities (McGarry 46). In December 1855 legislation for the abolition of slavery was passed. However, the slaves were not freed en masse, the emancipation process lasted two and a half decades (Achim 112), and some boyars even requested compensations for the loss of their slaves.

Moreover, the emancipation of the Roma from slavery did not include land grants, therefore even the integration in a physical space remained unresolved. Besides the worst paid jobs in society (those that Romanians would not take), old trades remained the main source of income (Achim 6). As slaves, the Roma could travel in order to provide various services (blacksmithing, gold-panning) in order to pay taxes to their masters. The lack of land property and nomadism were and remain interconnected. After the abolition of slavery, no specific integration policies were implemented, and even though during the interwar period an evolution of the Roma population towards modernisation was noted (Achim 153-159), no political and social support to consolidate these trends were provided. Furthermore, from a historical point of view, the Roma population was not listed among the country's minorities, and the minorities legislation made no reference to it. The nationalistic exclusive views did not target the Roma people before the Antonescu regime, with its racist policies (Achim 163185; Ioanid), culminating with the 1942 deportation of 25,000 Roma people to Transnistria. During the long communist period in Romania, the Roma continued to go unrecognized as an ethnic minority, and to be treated as a social category; no special policies to increase access to education, and to offer support for organizational structure 
were enacted. The marginal status, the low level of education and the lack of access to social resources act as constraints preventing structural emancipation. The structural inequality and epistemic injustice (Shmidt and Jaworsky 27) resulting from their longterm low and marginal social status, has marked the Roma's entire history in Romania. Moreover, a major gap in the cultural memory of Roma is obvious, including a general overlook of "the plight of Romani women and their ordeal" (Asavei 2019, 2). The stereotypical Roma women's cultural representations continue to hinder the knowledge of and engagement with women's memories and life experiences, the official public discourse related to Roma people being largely influenced by "centuries of historical injustices and strategic policies of forgetting the past" (Asavei 2019, 11).

Closely analysing the connections between past and remembrance, and the spatial dimension of the past, Ewa Mazierska notes the importance of space as a means to convey histories and memories, concluding that in order to study history, one should pay attention to its physical embodiments $(6,8)$. Jan Penrose writes that, besides the material dimension of space, the relationship between space and human life includes both the material and emotional latent powers of space, and that human beings only "begin to harness these sources of power when they transform space into places and territories" (279). Therefore, the control of space is considered "an extremely potent component of power relations" (Penrose 279-280). Territoriality generates both unity among the members of the same group acting on the same space -, and division marking the separation between us and others, while the association with a specific territory impacts the access to resources and social development. Moreover, the connections with specific territories are reinforced through history, memory and "symbolic transference" stories about origins, connecting people and places (Penrose 282). The control of a space reflects the group's needs and values and the societal exclusion and subordination of marginal groups is interconnected with this powerlessness. Furthermore, the exclusion zones are not limited to the "geographical and material marginalization of Roma communities but also... (to the) active exclusion of Roma from public life" (McGarry 88). The spatial segregation is grounded in the same "territorial exclusion" (McGarry 52) and the negative ascription of Roma people, indicating the complex interplay between territoriality, belonging and power, spatial marginalization and exclusion are signs of social exclusion. Segregation reinforces the 53 
existing social discrimination, continuing the idea that people are not equal, as they are not defined by their similarities but by their social differences. As a rule, the majority and the institutional forms of power governing a specific territory have consigned the Roma people to marginal, liminal spaces, clearly separated through physical and common-knowledge demarcation signs. Spatial separation reinforces social distance. Power relations acts on space itself, transforming it into an instrument of social discrimination and abusive practices (such as the case of eviction policies). As territorial exclusion intersects with ethno-spatial segregation, the Roma population's access to education and social resources decreases, and the Roma "become defined by their weaknesses and their victimization rather than by their contribution to society" (McGarry 55). The negative ascriptions and inferior status are defined as a phenomenon determined not only by individual assertions, but also sustained "via culture" (McGarry 67) and indicating structural injustice, as separation "actively orders space and produces hierarchies of belonging” (McGarry 88).

The same association between spatiality and Roma people, in fact the lack of specific territory and the resulting non-belonging status, establishes the idea that the Roma lack a commemorative culture. This assumption has been widely accepted and propagated in both the public and the academic discourse, and it has furthermore generated several generalizations dominating academic, media and popular culture, such as the assumptions that, unlike other communities, the Roma people have no cult for the past or interest in historical records, that a weak will to remember defines the Roma communities, and that the low interest in history and preservation of memory is generated by the absence of a written tradition (Asavei 2020, 111). However, written sources are expressions of institutional practices and of political and social agency, and are usually associated with, and the result of power relations. To all this reductive "Western-centric frame" (Tlostanova, Thapar-Björkert, Koobak 82) knowledge generating the premise of Roma people's indifference to remembering, one must reply by discussing the circumstances that silence or obstruct testimony: "the lack of infrastructure, the bureaucracy of the archives, and the strategic politics of forgetting" (Asavei 2020, 19). 


\section{Re-enactments of the hierarchy of existence: intersectional dimensions}

The hierarchy of belonging produces a hierarchy of existence, and structural injustice, which forms the basis for the future development of power relations. This paper discusses epistemic injustice (Fricker) as a form of structural injustice to which Roma people have been subjected, based on intersectionality. Cinematographic representations and visual reworkings of the hierarchy of existence mediate the understanding of power relations, as artistic performances can "challenge the habits of historical remembering and its politics of oblivion" (Asavei 2019, 1). Epistemic injustice is discussed in Miranda Fricker's two-stranded approach: testimonial injustice and hermeneutical injustice. Hermeneutical injustice, "caused by structural prejudice in the economy of collective hermeneutical resources," marks the Roma social status. As a result of "a gap in collective interpretative resources" the Roma people are much disadvantaged in relation with their own social experience, despite the fact that rendering this experience intelligible "is strongly in their interests"; their hermeneutical marginalization in terms of participation in the practices that generate social meaning determines the inadequate conceptualization and ill-understanding of their social experiences (Fricker 6-7). Testimonial injustice is "caused by prejudice in the economy of credibility," through the decreased level of credibility offered to a speaker's words based on the speaker's identity and on the prejudicial stereotype associated with it (Fricker 1, 4). Both injustices have colluded in establishing and perpetuating the Roma people's structural injustice and its institutional and cultural forms. Two dimensions of structural discrimination targeting the Roma as a knowledge and understanding subject are examined: "testimonial injustice, in which someone is wronged in their capacity as a giver of knowledge; and hermeneutical injustice, in which someone is wronged in their capacity as a subject of social understanding" (Fricker 7). The social injustice was doubled by the low hierarchical place allocated to the Roma, which "has shaped ongoing epistemic injustice - the systematic negation of the capacity of Roma to be producers and givers of knowledge, to make sense of their own social experiences and to obtain access to testimonial exchange" (Shmidt and Jaworsky 33). Besides epistemological injustice, structural intersectionality must inform the understanding of power relations and the structural injustice they generate. Kimberlé Crenshaw points out that the 55 
intersectional failures of the past propagate themselves and determine the current failures. The intersectionality framework is used in direct correlation with the vulnerability state in order to address multiple overlapping failures and discrimination: race and gender disempowerment, patriarchal domination, state violence, etc. The Roma anti-racist political discourse focuses on issues related to racism and fails to address the gender dimension and to take into consideration the women's social experience (Oprea). An intersectional analysis and the use of intersectional representations projected through visual artistic expressions can render visible repressed past experiences, systematic exclusion and epistemic injustice.

Through its structure, the diverse forms of media that were used, and its western cinema source of inspiration, Aferim! fuelled the discussion around the fictional practice of re-enacting the past. Several outcomes were connected to the film's chanelled force of making the audience members to examine their own racism, by holding up "a mirror reflecting present social attitudes towards the Other" (Pieldner 95). Such identified outcomes reflect the film's intermediality as a source of mobilisation against any idea of realist representations of historical reality (Pieldner) and "the impotence of historical didacticism," apart from the "historical truth's fragility" in terms of providing consensus in relation to events "whose dominant understanding is rooted in political erasure across long periods of time" (Popa 13-14). The decolonial stance acts differently in terms of tackling difficult and memory-challenging topics. Aferim! reveals the structural inequality and violence dominating the social order by using various narrative and visual mechanisms to fracture the re-enactment of the dominant historical narrative and to make the spectators acknowledge the artificiality of the entire process and the reality of the ongoing racist attitude dominating the Romanian society. The collage effect (Pieldner 100), the archaic language and the characters' excessive use of old proverbs and sayings, as well as the bloopers, which were intentionally kept in the film and which reveal the film artificial fabric, disturb the illusion of realist representation, opening for the audience a door between past injustice and current discriminatory practices, or between latent racism, kept under control by the audience's caution about the resulting social blame, and racism manifestations, socially accepted in the film (Ferencz-Flatz 129). 
While Aferim! departs from the re-enactment of the past from a position of power by introducing ruptures in the dominant narrative, Letter and Written elaborate on power relations by focusing on the Roma characters' interactions with the external space, using de-territoriality as cultural memory and aesthetic practice. The established connections with the physical space summarise the power relations and the deeplyentrenched foundations of structural inequality. Both films offer complex tools for comprehending the Roma people's non-belonging state, its marginal social status and its long history. The Roma characters are forced to move through an estranged territory that refuses to accommodate them. Maria from Letter is working in a household where her presence as a slave is required to be as quiet as that of a ghost and limited to specific places; the space she inhabits and where she has hidden the letter has nothing in common with the territory portrayed by the film as the site of power relations where her son's fate is decided. The visual opposition between the luxury of the house and the marginal spaces inhabited by the Roma characters, as well as the visual fabric of light and shadow mirrored by the characters' expressions point to the current physical segregation of the Roma community, to marginality and to the feeling of non-belonging. Pardica, the head of the family in Written/Unwritten is forced to travel carrying with him the non-belonging state: he is clearly feeling uneasy in the hospital interior where his underage granddaughter is having her child and he is forced to travel in order to bring his daughter to hospital, so as to comply with the rules imposed by the authorities. The hospital space is becoming a site of relationship of power, where the Roma characters are forced to acknowledge their non-belonging state of existence, as the documents implemented and verified by the state officials indicate their structural exclusion. The segregation and marginality re-create injustice and inequality through a vicious-circle movement: unwilling to interact in $\mathrm{n}$ environment grounded in stereotyped thinking and prejudicial attitudes and too busy finding means of subsistence, the Roma characters avoided renewing the official papers attesting their existence and family history. Furthermore, each negative interaction with the authorities and the lack of viable models of individual agency strengthen and deepen their exclusion. The visual and narrative deterritorialization practice acts by revealing the non-belonging state governing the Roma's lives as the direct result of state policies and general discrimination. 
The structural intersectionality of overlapping ethnicity and gender is tackled here through different visual and narrative mechanisms. While Aferim! and Letter focus on social structure and power relations, both indicating the low status of Roma people, Written/Unwritten looks at the long-lasting effects of structural discrimination and injustice on individual lives. In terms of the gender dimension of discrimination and injustice, the Roma woman has almost no voice in Aferim! and in Letter; while in Written it is only at the informal level that the woman is seen as a possible messenger between the patriarchal context of the Roma family and the Romanian society - prone to discrimination. The only woman who is elaborating her discourse facing the male figure - the representative of the patriarchy - and also the state representatives is the grandmother, who acts as a mediator, appeasing both sides of power and authority. She calms the husband, even if she is incriminated for the lack of supervision that led to the young girl getting pregnant, she is amiable with the medical staff, apologising for her husband's behaviour, she encourages her stepdaughter to let go of her anger for the past and re-bond with her daughter, etc. The young mother has no voice, and neither does her younger sister, who only agrees with her father/grandfather when advised to keep herself out of trouble and to continue to follow her formal education in school. For Pardica, education is the only option that his granddaughters have in order to evade the vicious circle of social marginalization and exclusion in which his own daughter was caught. He does perceive the structural injustice that underpins his family members' social status, but by the end of the movie he stops at indicating his understanding of this hermeneutical injustice. The double marginalization of Roma women should be discussed in relation to the agency issue, as the "lack of consideration for the role of agency and individual choice (...) represents a key limitation for emancipating Roma in the development of their own identities" (Shmidt and Jaworsky 230). By narratively and visually representing women figures acting and engaging with the social realities and reworking power relations, the Roma women can be encouraged to reshape and express their agency in facing the representatives of no matter what authority. It is quite possible that the grandmother figure does not correspond to the ideal of a well-educated woman who actively acts upon the external world and is fully responsible for her life path; however, her agency is worth considering. She raised the two girls abandoned by their mother, she understands and supports them unconditionally, she opposes in her 
own fashion her husband's patriarchal authority, she teaches the young generations the lesson of self-forgiveness, and, in the end, through her engagement and mediation, everyone celebrates the birth of the new baby and accepts to reconnect their lives and memories. By showing various models of agency and relationships the film makes the audience perceive its own limitations in their knowledge of epistemological injustice and it showcases the reductive colonial lens through which human beings and the social world are perceived.

All three films detail the social hierarchy and the fact that social relations are vertical, not only between boyars and slaves, rulers and plain people, but also between close social categories, various ethnic groups, and between those separated by age and gender. ${ }^{1}$ Aferim! presents "a network of established forms of violence - patriarchy, antisemitism, homophobia, all-encompassing xenophobia, and all of them supporting each other" (Lazar and Gorzo 304). The social fragmentation is extremely elaborated and it determines repetitive exclusion. Discrimination and inequality govern this exceedingly violent society; individuals from different ethnic groups devalue each other: those who have a better material condition discriminate against others, the adults oppress the children, etc. For example, the constable from Aferim - the representative of the law ${ }^{2}$ - is verbally and physically humiliating and harming almost all the people he encounters. Women are treated as property - their representations are constructed around the image of slave, servant, or whore, and when they are no longer young they are treated as completely useless and as images of the devil itself. 3 When they request to be treated as human beings, they are reminded of their insufficient knowledge of the state of affairs. The boyar's wife - beaten and imprisoned in her own house - appeals to her former status as the daughter of a wise man, and through this association with a man's authority she requests the acknowledgement of her status as a human being. The

${ }^{1}$ Popa writes that in Aferim! the hierarchical relationship between the various groups can be also identified through their costumes or by individual pieces of clothing: the Greek Phanariots, the lawkeepers, the musicians, and the poorly-dressed slaves and women; thus, the costumes do not function as national symbols but instead "assign to each character their different roles and specific status within the hierarchy of the times" (Popa 318).

${ }^{2}$ When meeting an ordinary man who request his help to find out who stole his horse, the constable refuses to help, humiliates the petitioner and continues to do his job as required by the boyar without considering for a moment to offer his services without discrimination.

3 An old woman carrying her sick husband is brutally mistreated; the Romanian peasant wife is humiliated and abused by the same Constandin who bragged to his son about the many women he had raped while he served as an army conscript. 
constable, who in fact has the duty to protect her, does little more than to recite old sayings and rules that describe women's low intellectual abilities and their weak nature. Hermeneutical injustice is forced upon those manifesting agency and the desire to go beyond their allotted status. The Roma women are treated as objects, pushed from a place to another, sold and beaten. Throughout the entire film the Roma are designated as "crows" - in Romanian cioară is an equivalent of the English "nigger"; they do not deserve any appreciation and furthermore their agency, when manifesting as opposition, even only at verbal level, is labelled as criminal. Even whining - when physically abused and tortured - is considered a trick played on with the abuser' mind. An epistemological injustice in the form of testimonial injustice is constantly at play.

In Letter, the Roma woman barely has a voice, but she cannot restrain her agency and she acts as a free woman. She lives in a house where she is reduced to a shadow moving and occupying marginal dark spaces, but through her actions she is pushing the physical boundaries, fighting also against social boundaries. However, the white aristocratic man does not give her much consideration, what draws his attention is her letter of forgiveness, a piece of paper written by another white rich man, a piece of paper in the hands of an illiterate slave Roma woman who is silently asking for his help to free her educated son. This letter is the one that convinces him to act in order to follow what he supposed to be his dead uncle's wish; he is acting on behalf of one of his family members who, even though dead, continues through his former social status to dictate the slaves' lives. And when the aristocrat's actions seem to harm other members of his family, he redraws his request to free the young boy slave, in fact the bastard son of his uncle. He decides to keep in slavery his own relative, disregarding the young boy's intellectual abilities and his high-level education. The epistemological injustice is at work here in both its forms: hermeneutical and testimonial. The Roma woman's experiences of injustice, including her exposure to possible sexual abuses, are reinforced by being intergenerationally transmitted to her son. He is kept around by the boyar's childless wife in order to remind her about her late husband. His slave status defines him as a living possession forced to renounce his capacity to act as a free agent. The one who acts is his mother, who plans carefully every step, deliberately observes and calculates the best way to succeed, etc. However, her free will and agency actions are invalidated when she is forced to silently and motionlessly look on while her son is 
repeatedly slapped and humiliated after the boyar's wife finds out about the failed attempt to have him forgiven of slavery.

\section{Visual expressions and narratives of deterritorialization}

The deterritorialization practices causing the borders between past and present, fiction and reality to become porous, and allowing the audience to confront its own prejudices and stereotypes are the result of a series of dialectical oppositions that render visible the trans-temporal and trans-spatial nature of discrimination and injustice: movement versus stillness, presence versus absence, light versus dark, outside versus inside.

Clearly opposed to the stereotyped model of the Roma traveller, the three movies discussed here indicate the forced movement to which the Roma characters are subjected by external forces; they are even carried like objects, as in the case of Carfin and Tintiric. When they move of their of accord they are merely trying to escape their slave fate (Carfin and Tintiric), and (re)take control over their own and/or over family members' lives (Maria and Pardica). In this dialectic of movement versus stillness the characters' gaze has its own role as deterritorialization practice by both addressing the audience's self-acknowledgement of its own discriminatory actions, and sometimes acting as a precursor of individual agency. Some of the directors are using the characters' gaze in order to underline the structural discrimination and to go beyond the confinements of the specific territory where the action is taking place by showing the porous border between the films' re-enacted events and the audience's reality, in a trans-spatial and trans-temporal movement. The audience is sensitized to the topic of structural inequality, present even at the level of the gaze: what the characters are allowed to see, and in what manner structural injustice is shaping their visual frame.

The Roma characters are forced to travel, in a socially and physically impelled movement contrasting with the generally accepted narrative of the Roma as natural travellers, moving according to their free will. The images of Carfin from Aferim! carried on horseback across a territory where his free will has no role impact the audience's grasp of inequality and discrimination. Carfin has his legs in stocks, draped uncomfortably, belly-down across the nape of Costandin's horse. He is facing the ground, his gaze is forcibly directed to the earth, to the return path which he did not choose but on which he is being led. He is forced to look down, to embrace his low 61 
status. Throughout this entire return journey Carfin's gaze is directed by his hierarchical superiors and he is allowed to look up - not to see the sky but the faces of his perpetrators - only at the end of the journey, when he is stripped of yet another part of his identity (here in terms of male body existence). As a slave he was already less than a human, and at the end of the film he is less than a man, the castration being in the perpetrators' eyes an instrument for making him genderless. Carfin is not the only one who does not travel of his free will, none of the Roma people from Aferim! are travelling willingly, they are forced by social circumstances to be on the move in order to make a living or even to save their lives. They are not travelling through spaces; they are forced to move through territories in which even their gaze can be restricted. A still frame from Aferim! shows the constable's young son riding and carrying the Roma child on his horse. Their bodies lean onto one another, to make their resemblance more visible to the audience; however, their social condition is defined by more than their clothes and shoes. Ioniță is looking directly at the camera, he is facing the world through the camera eye, while the Roma child's body is slightly turned away and his eyes are looking sideways; his gaze is avoiding direct contact with the camera and with the audience. A reworking of the inequality of the time is visually processed in order to show the ongoing discrimination and to reiterate the Roma's non-belonging status. The Roma characters are portrayed in outdoor spaces, their presence is not commonly detected indoors and when it is, their place is in shadow, looking sideways (just as Carfin when seated at the constable's table), hiding in marginal or adjacent spaces of the house (for example, in the attic), and generally their presence is not noticed - an unseen existence, except when a scapegoat is sought.

In Letter, Maria features in a different story of gaze. She does not limit herself to looking directly at the boyar' eyes when the fate of her child is at stake. She is keeping secret her letter of forgiveness, she is trying to free her son and she acts in such a manner as to not attract the boyars' rage. However, her penetrating gaze, always coming from the shadow of the dark spaces where she is forced to dwell, is a visual expression of both the structural inequality and the hermeneutical injustice that hinder Roma's knowledge over their own condition and impede their actions. Light underscores the social hierarchy and implicitly the hierarchy of existence: the higher the social position the better lit the characters and their surroundings. Maria is on the move when acting of 
her own free will, trying to free her son. Through her agency, expressed as the transgression of the physical territory and the questioning the power relations, the borders of the hierarchy of existence become porous. Individual agency, despite its temporal failure, is indicated as fostering mechanisms of overcoming structural injustice, both in its hermeneutical and testimonial form. Maria does not lower her gaze when the lady of the house repeatedly slaps her son. She continues to look, with her eyes full of tears, upon her son's humiliation and, through the camera's movements, into the eyes of the audience, thus addressing directly both her son's failed destiny and the audience's lack of acknowledgement of ongoing injustice and discriminatory practices.

Pardica, the grandfather in Written, avoids direct contact with the authorities until the end of the film; his gaze is filled with conflictual and frustration energy. He is acting like a hunted man, one burdened by countless worries and trapped in a dead-end marginality, despite his efforts to raise and educate his daughter/granddaughter so that she can have a better life and escape the vicious circle of intersectional discrimination (gender and ethnicity, in this case). None of the surroundings accommodate him: neither the hospital interior, nor the geographical space through which he drives, a space of poverty and marginality, nor his daughter's courtyard. All the interactions and the behaviour attached to them are played out as a confirmation of the onlookers' preexistent negative thoughts and expectations. Two scenes challenge the audience's stereotypical thinking about a Roma male's character, two moments of sensitivity and clear intimacy between the grandfather and his granddaughters: the dialogue in the car and his gentleness when interacting with his great-granddaughter. A subtle opposition between outdoors and indoors is played out: hospital interiors, car interiors, an impoverished outdoor space, and the physical dimensions reinforce the non-belonging state. All three films re-work the territory by focusing on its role in generating ongoing discrimination and re-enforcing the hierarchy of existences and the feelings of nonbelonging. Furthermore, Written/Unwritten brings forward a powerful expression of the absence-presence opposition correlated with the hermeneutical injustice. In Pardica's terms: "I need to believe you, but you don't need to believe us." When the official documents attesting blood relations are discussed and the medical staff question the family connections, Pardica loses his temper and plays the same card of distrust, directly targeting the doctor who has to fill the forms and who had also delivered the 63 
baby. Pardica uses the same arguments, questioning the existence of a connection between his granddaughter and the baby girl, insinuating that the personnel could easily switch the babies, since he was not in the delivery room to see with his eyes the baby being delivered. The doctor insists that she was there and that they need to believe her when confirming the mother-daughter relationship, while Pardica concludes with his phrase resuming the testimonial injustice: one testimony prevails over another only based on its author. Existence itself as presence attested from above and measurable through written documents is considered questionable otherwise, especially when judged with the epistemological instruments of the social system that continues to perpetuate structural inequality.

\section{Conclusion}

The territories are created through power relations, they mediate specific experiences for specific people and recreate the hierarchies that were originally imprinted upon them. Moreover, the created territories determine people's experiences, generating a vicious circle, continuously re-enacting an entangled story of structural injustice and vulnerability. The hierarchy of belonging creates and recreates a hierarchy of existence. Power relations are cinematographically contextualized by the nature of the settings in which they are represented. The films analysed here depart both from the historical reenactment of the past and from the dominant narrative grounded in discrimination and inequality, by stimulating dialogical memories. They draw attention to the Roma's vulnerability and to their efforts to create personal and community spaces in the middle of territories where marginalization and segregation are practised, to constantly carve out spaces for their existence.

By engaging with structural inequality and by inviting the audience to address its own racism, discriminatory practices, prejudices and harmful labelling, the cinema contributes, alongside arts and literature, to challenging the dominant narrative that overlooks the Roma's historical and ongoing structural injustice and propagates this lack of awareness in the general population. Therefore, through cinema reworkings, a 'dialogical and dialectical relationship' (Popa 309) with the continuous discrimination of the Roma people and its historical roots can be fostered. Through visual and narrative deterritorialization practices the films analysed here draw attention to the Roma's 
memories and experiences and to the audience's role in perpetuating the seclusion, marginalization and non-belonging state of existence. Confronting both hermeneutical and testimonial injustice, the films can contribute to creating space for individual agency and personal narratives including the Roma people's perspective, their knowledge and understanding over their own history.

\section{References:}

Achim, Viorel. The Roma in Romanian History. Central European University, 1998.

Brown, Tom. Breaking the Fourth Wall. Direct Address in the Cinema. Edinburgh University Press, 2012.

Asavei, Maria Alina. "Artistic memory and Roma women's history through an intersectional lens: The Giuvlipen Theater." European Journal of Women's Studies (2019), pp. 1-15. doi:10.1177/1350506819846163/.

---."'Call the witness': Romani Holocaust related art in Austria and Marika Schmiedt's will to memory." Memory Studies 13, no. 1 (2020), pp. 107-123.

Bogdal, K-M. "Europe Invents the Gypsies. The Dark Side of Modernity." Eurozine. Accessed 29 June 2021. http://www.eurozine.com/articles/2012-02-24-bogdalen.html.

Crenshaw, K.W. “On Intersectionality.” Keynote Lecture, Southbank Centre. Accessed 15 June 2021. www.youtube.com/watch?v=-DW4HLgYPlA.

---."Mapping the Margins: Intersectionality, Identity Politics, and Violence against Women of Color." Stanford Law Review 43 (6): 1241-1299.

Davis, N.Z. Slaves on Screen: Film and Historical Vision. Cambridge, Harvard University Press, 2000.

Erll, Astrid. "Traumatic pasts, literary afterlives, and transcultural memory: new directions of literary and media memory studies." Journal of Aesthetics \& Culture 3, no. 1 (2011): 1-5. doi: 10.3402/jac.v3io.7186.

---. "Travelling memory." Parallax 17, no 4 (2011): 4-18. doi: 10.1080/13534645.2011.605570.

Ferencz-Flatz, Ch. Incursiuni fenomenologice în noul film românesc. Tact, 2015.

Fricker, M. Epistemic Injustice: Power and the Ethics of Knowing. Oxford University Press, 2007. 
Gay Y Blasco, P. "Picturing 'Gypsies': Interdisciplinary Approaches to Roma Representation." Third Text 22 (3): 297-303. doi:10.1080/09528820802204235.

Goff, S. "Chain reaction: meet the first Romanian film director to tackle Roma slavery on screen." Calvert Journal, 7 December. www.calvertjournal.com/articles/show/5109/chain-reaction-romanian-directorradu-jude-aferim-roma-slavery.

Hadziavdic, H. and H. Hoffmann. "Moving images of exclusion: Persisting tropes in the filmic representation of European Roma." Identities. 24 (6), 2007, 701-719.

Hoffman, J. "Aferim! Review: a Brutal Manhunt Loaded with Laughs." The Guardian January 20. https://www.theguardian.com/film/2016/jan/20/ aferim-review-abrutal-manhunt-loaded-with-laughs.

Imre, A. "Screen Gypsies." Framework: The Journal of Cinema and Media 44 (2), 2003, 15-33.

Ioanid, R. The Holocaust in Romania: The Destruction of Jews and Gypsies Under the Antonescu Regime, 1940-1944. Ivan R. Dee, 2000.

Iordanova, D. "Images of Romanies in Cinema: A Rough Sketch." Framework: The Journal of Cinema and Media 44 (2), 2003, pp. 1-8.

---. "Mimicry and Plagiarism. Reconciling Actual and Metaphoric Gypsies." Third Text. 22 (3), 2008, pp. 305-310.

Jelača, D. "Youth after Yugoslavia: subcultures and phantom pain." Studies in Eastern European Cinema. 5 (2), 2014, pp. 139-154.

---. Dislocated Screen Memory Narrating Trauma in Post-Yugoslav Cinema. Palgrave Macmillan, 2016.

Kiang, J. "Berlin review: Berlin Best Director Radu Jude's bawdy, brilliant 'Aferim!"” IndieWire. 17 February. www.indiewire.com/2015/02/berlin-review-berlin-Bestdirector-radu-judes-bawdy-brilliant-aferim-267104.

Lazăr, V. and Gorzo, A. "Aferim! - ceva nou în cinemaul românesc." In Politicile filmului. Contribuţii la interpretarea cinemaului românesc contemporan, edited by Gorzo, A. and State, A., 301-312. Tact, 2014.

Mazierska, E. European Cinema and Intertextuality. History, Memory and Politics. Palgrave Macmillan, 2011, 
METACRITIC JOURNAL FOR COMPARATIVE STUDIES AND THEORY 7.2

McGarry, A. Romaphobia: The Last Accepted Form of Racism. The University of Chicago Press, 2017.

Murtic, D. Post-Yugoslav Cinema Towards a Cosmopolitan Imagining. Palgrave Macmillan, 2015.

Oprea, Al. "Re-envisioning social justice from the ground up: Including the experiences of Romani women." Essex Human Rights Review 1 (1), 2004, pp. 29-39.

---. "Intersectionality backlash: A Romani feminist's response." Journal of the European Roma Rights Centre. 21-24. http://www.errc.org/uploads/upload_en/file/roma-rights-2-2009-multiplediscrimination.pdf.

Penrose, J. "Nations, states and homelands:territory and territoriality in nationalist thought." Nations and Nationalism 8 (3), 2002, pp. 277-297.

Pickering, M, Research Methods for Cultural Studies Research Methods for Cultural. Edinburgh University Press, 2008.

Pieldner J. "History, cultural memory and intermediality in Radu Jude's Aferim!" Film and Media Studies 13(1), 2006, pp. 89-105.

Popa, D. "Narrating the past: Cultural memory and Romanian identity in Aferim!" Journal of European Studies. 48 (3-4), 2018, pp. 308-326.

Radstone, S. "Cinema and Memory." In Memory: Histories, Theories, Debates, edited by Radstone, S. and Schwarz, B., 325-342. Fordham University Press, 2010.

Shmidt, V. and Jaworsky, B.N. Historicizing Roma in Central Europe: Between Critical Whiteness and Epistemic Injustice. Routledge, 2021.

Till, K.E."Artistic and activist memory-work: Approaching place-based practice." Memory Studies. 1 (1), 2008, pp. 99-113.

Tlostanova, M. Postcolonialism and Postsocialism in Fiction and Art. Resistance and Re-existence. Palgrave Macmillan, 2007.

Tlostanova, M., Thapar-Björkert, S., and Koobak, R. "The postsocialist 'missing other' of transnational feminism?” Feminist Review. (121), 2019, pp. 81-87.

Trehan, N., and Kóczé, A. "Racism, (Neo-)Colonialism and Social Justice: The Struggle for the Soul of the Romani Movement in Post-Socialist Europe.” In Racism Postcolonialism Europe, edited by Huggan, G. and Law, I., 50-74, Liverpool University Press, 2009. 
Van Baar, Huub. "Europe's Romaphobia: Problematization, Securitization, Nomadization.” Environment and Planning D: Society and Space 29 (2), 2011, pp. 203-212. 